- Ethical challenges Limitation of treatment 3; Withdrawal of treatment 2; Discharging home with TPN 2; Refusal of consent for surgery 1; Escalation of pain medication 1; Burden of treatment 1; Experimental treatment 1.

Legal issues:

- One case was taken to court, seeking approval to withdraw artificial hydration on the grounds of child's best interest

Discussion Neurology consults made up $25 \%$ of the RCRS. They pose a particular challenge, with complex, often incurable disease, with either no evidence-based treatments or only palliative therapies available. So, ethical dilemmas regarding treatment and end of life decisions are common.

The associated neuro-disability, and life-limiting aspect means social care and palliative care should be involved early on. Furthermore, discussions around care plans and DNAR should be prioritised.

The RCRS has a vital role in helping resolve conflict between the clinical team and parents, and supporting them to come to a consensus on management. It is rare that a court application is required.

Future improvements may involve routine referrals to the RCRS, focused ethics' training for neurology clinicians, and prerequisite criteria for referral (e.g. having a second opinion and care plan).

\section{G474 CHILDREN, ORGAN DONATION AND ISLAM: A REPORT OF A MULTI-DISCIPLINARY DAY}

${ }^{1}$ M Aktas, ${ }^{2}$ R Kazmi, ${ }^{3}$ J Brierley. 'Durham University, Durham, UK; ${ }^{2}$ Chaplaincy Department, Great Ormond Street Hospital, London, UK; ${ }^{3}$ Department of Paediatric Bioethics, Great Ormond Street Hospital, London, UK

10.1136/archdischild-2018-rcpch.462

Purpose The day was established to look at organ donation in the Muslim community from deceased children. The BAME population has a lower rate of organ donation, but an increased need for transplantation - though this is known in children. Anecdotally, some Muslim parents and academics have suggested that organ donation is forbidden whereas other Muslim scholars think it acceptable: Two main sects: Shia Many scholars think organ donation and receipt permissible, though some suggest it's only permissible if organs go to Muslims. Sunni - some scholars do not accept brain death as human death. Re donation there are three main groups: donation permissible, not permitted or it is a 'grey area.'

Methods We explored these views in a multi-disciplinary and faith dialogue day with religious scholars, organ donation/ transplant specialities, young people, and hospital chaplains.

Themes in child- donation/transplantation emerged: need for organs; the demographics of child death and donation; the respectful process of donation in the setting of end-of-life care; retrieval and transplant of organs; paradox between families agreeing to transplant who would not agree to donation Both Sunni and Shia scholars explored their faith views about these issues and particularly the voice of the Prophet that forbade desecration of enemies after death was discussed, along with the appropriateness of its extension to the organ donation situation.

Results A panel convened to review the issues and find a way forward: (i) In general all felt the decision about whether to accept brain death as a definition of death was for the law for country to determine. (ii) Organ donation was a matter that should be decided by the parents of the child. (iii) No attendees felt organ donation to be forbidden by any religious orthodoxy, and that as Islam is a way of life represented by generosity, organ donation is acceptable - not least as most people will accept a transplant if they need one for them, or their child

Conclusions A leaflet for families about the Islamic views of donation is to be made. Muslim children who have received a transplant and the chaplains/scholars present together with donation/transplant staff will arrange education sessions in Mosques for families and the community.

\section{G475(P) NHS STAFF ATTITUDES AND OPINIONS TOWARDS THE USE OF SOCIAL MEDIA BY PATIENTS, FAMILY AND FRIENDS IN RELATION TO THEIR HOSPITAL EXPERIENCE}

\begin{abstract}
${ }^{1,2}$ AJ Shehadeh, ${ }^{1} \mathrm{G}$ Bull, ${ }^{1} \mathrm{~A}$ Crouch, ${ }^{1} \mathrm{~S}$ Hambrook, ${ }^{1} \mathrm{~A}$ Samejeu, ${ }^{1} \mathrm{D}$ Zeitlin. ${ }^{1}$ Paediatric Critical Care Unit, Royal London Hospital, Barts Healthcare Trust, London, UK; ${ }^{2}$ Paediatric Emergency Department, West Middlesex University Hospital, Chelsea and Westminster NHS Foundation Trust, London, UK
\end{abstract}

\subsection{6/archdischild-2018-rcpch.463}

Intro 'Over $60 \%$ of $13-17$ year olds have at least one profile on a social networking site, many spending more than two hours per day on social networking sites.'

American Academy of Child and Adolescent Psychiatry, February 2017.

Social media is increasingly employed by patients, families and friends (PFF/SM) to publicly express their thoughts and feelings about their hospital experience. It is well recognised that social media changes the way users communicate. Its unchecked use can disrupt established and effective communication channels such as PALS and face-to-face interactions.

Aim Primary survey of acute paediatric NHS Staff perceptions on the use PFF/SM to publicly document their hospital experience.

Methods Questionnaires were given to all staff, in the paediatric department at an inner London Children's Hospital.

The specifically constructed questionnaire looked at possible positive and negative impacts of social media use on aspects of a patient's attendance as outlined by the GMC Good medical practice (patient-staff relationships, clinical management, confidentiality and patient safety).

Results 94\% of respondents had previous personal-use experience with some format of social media. $75 \%$ had been involved in a situation where a patient's hospital experience had been documented on social media. Of this $75 \%$, one third reported that it was a positive experience and one third felt that it had been an overall negative experience.

Half of responders felt strongly that PFF/SM use would have an impact on clinical decision-making and interventions. However, whilst $41 \%$ were concerned that $\mathrm{PFF} / \mathrm{SM}$ use would affect patient safety, only $22 \%$ felt that it could cause a breach of patient confidentiality.

Discussion Social media etiquette and governance are still emerging. Unchecked public comments, about professionals or the services they provide, present evolving challenges for trusts. Our staff survey has shown significant concern about the impact of PFF/SM on patient safety and the perception that it could impact on clinical decision making. 
G476(P) THE IGNORED PERVASIVE FORM OF EMOTIONAL ABUSE: INTIMIDATING YOUNG CHILDREN FROM DOCTORS AND INJECTION

E Ebtihal. Paediatrics, Jazan University, Jazan, Kingdom of Saudi Arabia

10.1136/archdischild-2018-rcpch.464

Background Every child seems to have the normal level of fears towards certain subjects that started in early childhood and act as an assurance policy to protect the child from harm. Parents play the major role in reassuring their children and protecting them from fear and anxiety, on the other hand, they may behave to cause child fear by overprotection or sometimes by intimidating them to obey certain commands or to stop the annoying act. The acts of child intimidating behaviour by their parents constitute a pervasive and ignored form of emotional abuse. The aims of this study were to assess the psychological impact of the parenting trends towards intimidation of their children from doctors and injections and to assess its relation to some demographic variables (parenting relationship, parental ages, parental level of education, sex of the child, and if the child has chronic illness) and to the refusal of the medications.

Methods The study followed the descriptive analytical method and included the parents of 103 kindergarten children aged 3-6 years. Data collected using the scale of parenting trends in the period of September 2015 to January 2016.

Results Intimidating child from doctor and injections has a highly negative impact on the child psychologically. There are no significant differences in the degree of intimidation of the child from doctors and injections attributable to the parenting relationship (father, mother), the age of the parents, their educational level, the child sex, and the presence of chronic illness. 59\% of the parents link between this trend and the child refusal of the medications.

Conclusions Intimidation of the children from doctor and injections has a highly negative impact on the children psychologically and may contribute to their refusal of medications. No significant differences attributable to the demographical variables.

\section{G477(P) NON-BLANCHING RASH: THINKING OUTSIDE THE BOX}

${ }^{1} \mathrm{P}$ Desai, ${ }^{1} \mathrm{C}$ Yale, ${ }^{1} \mathrm{D}$ Herath, ${ }^{2} \mathrm{~J}$ Tobin. ${ }^{1}$ Paediatrics, Ipswich Hospital NHS Trust, Ipswich, UK: ${ }^{2}$ Cambridge University, Cambridge, UK

10.1136/archdischild-2018-rcpch.465

An 11-year-old girl presented to the Paediatric department with a non-blanching rash, which was vasculitic in appearance and tender to touch, but not pruritic. The typical feature was hyperaesthesia, starting on her left forearm. The child was well and afebrile, with no history of: musculoskeletal problems; red eyes; mouth ulcers; trauma or insect bites. The girl lived with her parents and two siblings, and had neither a past medical history nor family history of vasculitis.

At initial presentation, the paediatrician corroborated the GP's working diagnosis of shingles with neuropathic pain; the patient was given an extended course of acyclovir, plus amitriptyline. During follow up, the patient reported improved pain, whilst the rash had completely subsided.

However, two weeks later, the girl returned with a similar painful rash. Upon dermatological review, she received IV antibiotics for suspected chronic meningococcemia. Over the next eight months, the rash waxed and waned, and often healed completely.

She received, at various stages, diagnoses of: shingles with neuropathic pain; chronic meningococcemia; segmented pigmented dermatosis; cutaneous vasculitis; atypical HenochSchönlein purpura; and potential urticarial vasculitis.

Altogether, this patient had 13 paediatric outpatient appointments, one admission, two reviews in the acute paediatric unit and two tertiary dermatology referrals.

She had 29 blood tests, and numerous urine dipsticks. Her full blood count, coagulation screen, inflammatory markers and autoimmune screen were normal.

She received three courses of acyclovir, one course of antibiotics, regular analgesia, amitriptyline and six weeks of prednisolone.

She also had two skin biopsies, which reported an element of purpura without any vasculitis.

Given purpura without vasculitis, the revelation that our patient was a teenager going through a stressful period at school caused us to consider and discuss an exogenous cause (deliberate self-infliction). The rash's subsequent complete resolution within a few months strengthens this hypothesis.

Clinicians frequently care for children with complex or unconventional presentations. In an era of defensive medicine, we request a plethora of investigations and specialist opinions before diagnoses like self-inflicted injuries are considered. This case raises ethical questions about how far we should go in our pursuit of an intellectually satisfying definitive diagnosis.

\section{G478(P) WE WANT EVERYTHING DONE}

SV Rasiah, AK Ewer. Neonatal Intensive Care Unit, Birmingham Women's and Children's Hospital NHS Foundation Trust, Birmingham, UK

\subsection{6/archdischild-2018-rcpch.466}

Background Increasingly we are faced with some parents who want everything done for their babies in neonatal units although their neurodevelopmental outcome is likely to be extremely poor. This results in conflict with parents regarding the best interest of these babies and moral distress caused among the neonatal staff looking after them.

Case studies Case A: A 23 week infant who developed major parenchymal haemorrhagic infarct with midline shift and clinical seizures on day 3 of life. Parents were counselled of the very poor prognosis but declined re-orientation to palliative care. Baby never demonstrated a suck or gag reflex. Baby remained in low flow oxygen and required nasogastric feeds. Baby was eventually transferred to a paediatric ward and died following an aspiration episode.

Case B: A 24 week infant who became extremely sick before and following NEC surgery. We were never able to establish any enteral feeds. Despite multiple discussions with parents from neonatologists, paediatric surgeons and second opinion from another independent tertiary neonatologist, they refused re-orientation to palliative care. Baby subsequently died from multi-organ failure.

Case C: A 28 week infant with multi-organ failure and severe periventricular leukomalacia following a severe case of NEC requiring surgery. Despite seeking second opinions and multiple attempts at counselling parents, palliative care was declined. This case eventually went to court and the judgment 
was to re-orientate to palliative care which the parents accepted.

Conclusion These increasingly challenging ethical cases result in significant moral distress among neonatal staff that already operate in an high stress environment. In some cases it results in the prolongation of suffering of these babies. This impacts on the moral well being of the nursing and medical staff looking after these babies over this challenging period. We need to remain focused as advocates for these vulnerable babies and continue to keep their best interest at the heart of care we provide. Staff support is also paramount in ensuring that their moral distress is addressed and supported.

\section{G479(P) CAN PARENTS-TO-BE THAT FAIL TO ENGAGE WITH ANTENATAL SCREENING SERVICES HARM US ALL?}

${ }^{1,2} \mathrm{C}$ Kanaris. 'North West and North Wales Paediatric Transport Service, Manchester
University NHS Foundation Trust, Manchester, UK; ${ }^{2}$ The Centre for Social Ethics and Policy,
School of Law, The University of Manchester, Manchester, UK

10.1136/archdischild-2018-rcpch.467

I make a case in favour of a parental duty to engage with antenatal screening services and in utero therapies. I explore the question of whether ignorance of one's future child's genetic makeup in the antenatal setting causes harm, and if so whether we have a moral obligation to avoid it by employing antenatal screening and in utero therapies available to us. I review current philosophical theories on harm, as well as current clinical advances that can improve the health children that will come to exist I focus particularly on refuting arguments favouring one's alleged 'right to genetic ignorance' and argue that both Mill's Harm principle and Kant's definition of autonomy can be applied in the antenatal setting in order to protect future children. I analyse whether, where safe and effective in utero treatments are available and not up-taken, resulting in children being brought to existence in a more impaired state than they otherwise would have, amounts to harm. I also consider whether harm can be caused to parents themselves, siblings and wider society by a failure to engage with antenatal screening and in utero therapies.

\section{G480(P) THE EXPERIENCES, ATTITUDES AND PRACTICES OF NURSES WORKING IN A PAEDIATRIC INTENSIVE CARE UNIT CARING FOR BABIES AND CHILDREN AT THE END OF LIFE: A QUALITATIVE STUDY}

'P du Pré, ${ }^{1 J}$ Brierley, ${ }^{2} \mathrm{~J}$ Koffman. ${ }^{1}$ Paediatric and Neonatal Intensive Care Unit, Great Ormond Street Hospital, London, UK; ${ }^{2}$ Palliative Care, King's College London, London, UK

\subsection{6/archdischild-2018-rcpch.468}

Introduction Of the $74 \%$ of UK childhood deaths that occur in hospital, an increasing number - up to $65 \%$ - occur in PICU. There is little information about the impact of this on those who provide minute-to minute care of the children and their families, the bedside nurses.

Aims The objectives of this study were to explore the lived experiences, attitudes and practice of nurses delivering PICU end-of-life care (EOLC).

Method Maximum variation sampling: range of roles and clinical experience to identify potential participants who may hold different views.
Qualitative approach with face-to-face semi-structured interviews away from the bedside. (Build rapport, tackle hierarchy and enable undiluted, in depth, exploration.)

Researcher introduced broad topic areas, then specific questioning responsive to participant replies.

Areas: clinical background ('ice-breaker'); experiences caring for children at EOLC; view of what good outcome entails; any experiences taking children home or to hospice for EOLC.; challenges faced providing EOLC; discussions surrounding EOLC (who/when/how documentation. Recollected case EOLC done well and one where done badly

Interview process designed to maximise richest data. Face-toface interviews to obtain detailed investigation of participant's personal perspectives within complex systems. Qualitative methodology sought and preserved original lived experience of participants and offer insight into individuals' subjective livedexperiences, providing rich descriptions contextualised to participants personal settings and social meanings. Data recorded, transcribed and analysed thematically.

Results Seven participants. Main themes were facilitating factors and challenges faced providing optimal EOLC for children and families. Themes included: offering choice to families; meeting family's needs; past experience; relationships with families; conflict in a few hard cases; communication; uncertainty and lack of time. Participants consider they do this well most of the time and find this aspect of work hugely satisfying when done well but extremely hard when there are difficulties

Conclusions This study provided rich insights into the lived experiences of nurses caring for children at end of life in PICU. We demonstrated the values and models of good practice as well as the barriers encountered. There continues to be a need to advance the evidence base in order to improve this aspect of care.

\section{International Network of Paediatric Surveillance Units}

\section{GLOBAL SPREAD OF STEC AND MANAGING THE CONSEQUENCES}

${ }^{1}$ A Smith-Palmer, ${ }^{1} G$ Hawkins, ${ }^{1} S$ Couper, ${ }^{2} H$ Maxwell, ${ }^{2} B$ Reynolds, ${ }^{2} V$ Harkins, ${ }^{3} \mathrm{~L}$ Allison, ${ }^{3} \mathrm{M}$ Hanson. ${ }^{1}$ Health Protection Scotland, Glasgow, UK; ${ }^{2}$ Royal Hospital for Children, Glasgow, UK; ${ }^{3}$ Scottish E.coli 0157/STEC Reference Laboratory, Department of Laboratory Medicine, Royal Infirmary Edinburgh, Edinburgh, UK

\subsection{6/archdischild-2018-rcpch.469}

Shiga toxin-producing E. coli (STEC) was first recognised as a food-borne pathogen in 1982, when it was isolated during two outbreaks of haemorrhagic colitis associated with undercooked burgers in the United States. Since then, STEC has become established as an important global gastrointestinal pathogen.

STEC can colonise the gastrointestinal tract of wild, farmed, and domesticated animals and be shed in their faeces. Cattle are considered the most important reservoir for STEC in humans; infection in cattle is non-pathogenic.

Transmission to humans can occur as a result of direct contact with STEC-contaminated faecal material, from handling or petting animals or by exposure to faecally contaminated soil or vegetation during recreational or occupational activities. 